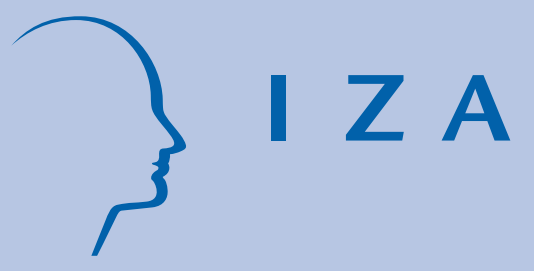

IZA Policy Paper No. 74

\title{
Labor Demand Effects of Rising Electricity Prices:
} Evidence for Germany

Michael Cox

Andreas Peichl

Nico Pestel

Sebastian Siegloch

December 2013 


\title{
Labor Demand Effects of Rising Electricity Prices: Evidence for Germany
}

\author{
Michael Cox \\ IZA and University of Cologne \\ Andreas Peichl \\ Nico Pestel \\ $I Z A$

\section{Sebastian Siegloch} \\ $I Z A$

\section{Policy Paper No. 74 \\ December 2013} \\ IZA \\ P.O. Box 7240 \\ 53072 Bonn \\ Germany \\ Phone: +49-228-3894-0 \\ Fax: +49-228-3894-180 \\ E-mail: iza@iza.org
}

IZA, University of Cologne, ISER and CESifo

The IZA Policy Paper Series publishes work by IZA staff and network members with immediate relevance for policymakers. Any opinions and views on policy expressed are those of the author(s) and not necessarily those of IZA.

The papers often represent preliminary work and are circulated to encourage discussion. Citation of such a paper should account for its provisional character. A revised version may be available directly from the corresponding author. 
IZA Policy Paper No. 74

December 2013

\title{
ABSTRACT \\ Labor Demand Effects of Rising Electricity Prices: Evidence for Germany
}

\begin{abstract}
Germany plays a pioneering role in replacing conventional power plants with renewable energy sources. While this is beneficial with respect to environmental quality, the energy turnaround implies increasing electricity prices for private households and firms. The extent to which this is associated with negative impacts on employment depends on the interrelationship between labor and electricity as input factors. In this paper, we estimate cross-price elasticities between electricity and heterogeneous labor for the German manufacturing sector. We use administrative linked employer-employee micro data combined with information on electricity prices and usage during the period 2003-2007. Our findings suggest that there is a weak substitutability between electricity and labor, when the production level is held constant. We find positive, but small conditional cross-price elasticities of labor demand with respect to electricity prices between 0.09 and 0.31 . In case of adjustable output, we find moderate gross complementarity with negative unconditional cross-elasticities ranging between -0.06 and -0.69 . Labor demand is affected differently across skill levels with low- and high-skilled workers being affected more than mediumskilled. Our estimates suggest that the announced increase of the EEG surcharge in 2014 would decrease overall employment in the manufacturing sector by 86,000 workers, a decline by 1.4 percent.
\end{abstract}

JEL Codes: J08, J23, Q48, Q58

Keywords: electricity prices, labor demand, employment, energy, Germany

Corresponding author:

Nico Pestel

IZA

P.O. Box 7240

53072 Bonn

Germany

E-mail: pestel@iza.org

*We are grateful to workshop participants at IZA Bonn for helpful comments and suggestions. 


\section{Introduction}

Germany plays a pioneering role in replacing conventional and nuclear power plants with renewable energy sources. In 2000, the Renewable Energy Sources Act ("Erneuerbare Energien-Gesetz", EEG) favoring renewable energies was passed. The benefit of the German "energy turnaround" is a reduction of greenhouse gas emissions by 11.9 percent between 2000 and 2011 (Umweltbundesamt, 2013). However, households as well as firms are faced with increasing electricity prices (Bundesverband der Energie- und Wasserwirtschaft, 2013), mainly due to the renewable energy surcharge according to the EEG, which subsidizes investments in renewable energy sources. Hence, while a transition towards renewable energies is beneficial with respect to environmental quality and improved health, a trade-off arises as it is associated with economic costs, such as negative impacts on industrial activity or labor market outcomes. Yet, little is known about these economic costs, which is especially true for potential employment effects. Increasing electricity prices may, however, have a non-negligible impact on employment, since particularly in the German manufacturing sector, electricity accounts for a substantial share of total production costs. Both the sign and the size of the effect of rising electricity prices on employment depend on the interrelationship between electrical power and labor as input factors, i.e., the cross-price elasticity between the two.

Recent studies concentrate rather on job creation possibilities through "green" investments and subsidies in the US and Germany (Deschenes, 2013; Frondel et al. 2010), whereas Aldy and Pizer (2011) as well as Ho et al. (2008) focus on employment effects of carbon taxation in the US. Berndt and Wood 1975) and Pindyck and Rotemberg (1983) analyze how capital, labor, energy and materials interact in US industries by estimating elasticities of substitution as well as cross-price elasticities between input factors using data on 25 industrial sectors with a time span ranging from 1947 to 1971. Several studies analyze the relationship between energy and labor demand for Germany. However, there are a number of limitations associated with these. Almost all are based on data from periods between the 1970s and the early 1990s, which may be problematic regarding changes in production technologies. In addition, they typically use highly aggregated industrial sector level data 
and some of them treat labor as an homogeneous input factor and do not differentiate between different skill levels. Kemfert and Welsch (2000) employ a general equilibrium model and use data aggregated to seven sectors (1970-1988), Falk and Koebel (2002) base their estimates on a data set that includes 26 industries over the period 1978- 1990 and a Box-Cox cost function. Koebel et al. (2003) analyze 31 manufacturing industries for a time span ranging from 1978 to 1990. Welsch and Ochsen (2005) estimate elasticities for the fully aggregated manufacturing sector (1976-1994), Agnolucci (2009) uses a sample covering six industrial sectors over the period 1978-2004.

So far, there are only few studies estimating cross-price elasticities between labor and electricity. Deschenes (2010) estimates elasticities for the US based on a sample covering twelve sectors for the period 1976-2007, while Henriksson et al. (2012) investigate industrial electricity demand in Sweden using a panel data set of 19 firms in the pulp and paper industry (1985-2004). Both studies do not account for heterogeneity in the workforce.

The aim of this paper is to analyze how rising electricity prices directly affect the demand for heterogeneous labor in Germany. Relying on a static labor demand model with multiple input factors (Hamermesh, 1993), we estimate the cost shares of input factors using micro data on a very disaggregated sectoral level. The main contribution is an estimation of the cross-price elasticities of heterogeneous labor with respect to electricity prices between 2003 and 2007 in the German manufacturing sector. We explicitly distinguish between elasticities conditional as well as unconditional on firms' level of output. The main database is administrative linked employer employee micro data from the IAB (LIAB), which we combine with data on electricity prices and consumption.

Our findings suggest that there is a weak substitutability between electricity and labor, when the production level of the firms is held constant. We find positive, but small conditional cross-price elasticities of labor demand with respect to electricity prices between 0.09 and 0.31 . Yet, as the scale effect dominates the substitution effect, we find negative unconditional cross-elasticities ranging between -0.06 and -0.69 . The magnitude of our estimates for cross-price elasticities varies substan- 
tially across different skill levels of labor input. While the demand for high and low skilled workers turns out to be moderately affected by electricity prices, the effect is close to zero for medium skilled workers. This suggests that further increases in the price for electrical energy in Germany (e.g., due to the EEG surcharge) would result in negative employment effects in the manufacturing sector.

The paper is structured as follows. In section 2 we illustrate the institutional background and present the development of electricity prices and consumption. Section 3 presents the empirical approach and Section 4 the data. We present, discuss and compare our estimation results in section 5. Section 6 concludes.

\section{Electrical Energy in Germany}

\subsection{Institutional Background}

The electricity costs of firms consist of several parts. Firms have to pay for the generation of electrical energy, which is traded at stock markets like the European Power Exchange (EPEX), as well as for the transportation by paying charges to the transmission grid operators $\mathrm{I}^{1}$ In addition, there are several taxes and levies on the usage of electrical energy. In Germany, the most important levy is nowadays the renewable energy surcharge according to the EEG. Its revenue is used to subsidize the generation of electricity from renewable energy sources like solar, wind or water. The general concept of the EEG is that operators of renewable power plants receive a guaranteed compensation for each produced unit of electricity over a period of 20 years in order to attract investments in these technologies. The level of the surcharge, a feed-in tariff paid by electricity consumers, is determined annually by the transmission grid operators and equals the gap between the compensation's total amount and revenues from trading renewable electricity divided by total electricity consumption. This surcharge is added to the electricity bill of private households and firms, which are not exempted (see below).

An important mechanism which has contributed to the strong growth in the

\footnotetext{
${ }^{1}$ Grid charges differ a lot across firms depending on their power consumption as the costs of transportation also depend on the voltage.
} 
surcharge is the "merit-order-effect". At the spot market (EPEX) the electricity produced with the lowest marginal costs is sold first (merit-order), while the bid of the last sold contingent marks the electricity price. As the green power plants have very low marginal costs (no or low fuel, operating and maintenance costs), conventional power plants with higher marginal costs are crowded out. An increase in the supply of renewably generated electricity therefore leads to a lower electricity price at the spot market which decreases the revenues of the grid operators. Mechanically, this widens the gap between the (guaranteed) compensation for renewable electricity and the market revenues. This, in turn, raises the EEG surcharge. Hence, an increase in the supply of renewable electricity lowers the market prices at the EPEX but raises the EEG surcharge (Erdmann and Zweifel, 2010). Total electricity prices for small to medium electricity consumers therefore rise as they benefit less from low prices at the spot market but have to pay the full EEG surcharge. Energy-intensive firms are, in contrast, more likely to buy electricity near-term at the spot market and are largely exempt from the EEG surcharge (Sensfuß, 2011) 2 In 2007, 382 firms benefited from the exemption clauses $(\mathrm{BMU}, 2007)$ which accounts for only 0.14 percent of the firms in the industrial sector (Statistisches Bundesamt, 2013). On the other hand, approximately 72,000 GWh of the industrial power usage was exempt which equals one third of overall electricity consumption. This illustrates that only few firms with very high power usage, mainly associated with the chemical, metal and paper sectors, benefited from the exemption clauses $3^{3}$

${ }^{2}$ For example, in 2003, firms with an annual electricity consumption of at least 100 GWh and an electricity cost share of at least 20 percent, paid only 0.05 cent $/ \mathrm{kWh}$ for each $\mathrm{kWh}$ consumed above 100 GWh. In 2004, these exemption clauses were expanded. Firms with an annual electricity consumption of at least $100 \mathrm{GWh}$ and an electricity cost share of at least 20 percent paid the reduced EEG surcharge of 0.05 cent $/ \mathrm{kWh}$ for total electricity consumption. Additionally, firms with an annual electricity consumption of at least $10 \mathrm{GWh}$ and an electricity cost share of at least 15 percent paid the reduced surcharge of 0.05 cent $/ \mathrm{kWh}$ for 90 percent of their consumed electricity. For the remaining 10 percent the establishments had to pay the regular EEG surcharge which was 0.51 cent/kWh in 2004 .

3 There are further exemption clauses for other taxes like the Electricity Tax ("Stromsteuer"). See Küchler and Horst (2012) for further information on industrial exemption clauses for electricity. 


\subsection{Development of Prices and Consumption}

Figure 1 shows the development of average electricity prices in the industrial sector in Germany from 1998 to 2013 for an annual usage of 160 to 20,000 MWh. The main reason for the vast decrease in the late 1990s is the deregulation of the German electricity market in 1998 which reduced excess capacities of power plants in Germany. The year 2000 marks the turning point as the prices increase from this year onwards. Rising prices of natural gas and coal after the turn of the millennium raised the prices for conventional electricity. In addition, the certificate trading of the European Union and "green" taxes on electricity led to a vast price increase (Frontier Economics and EWI, 2010). The first increase in the tax burden in 2003

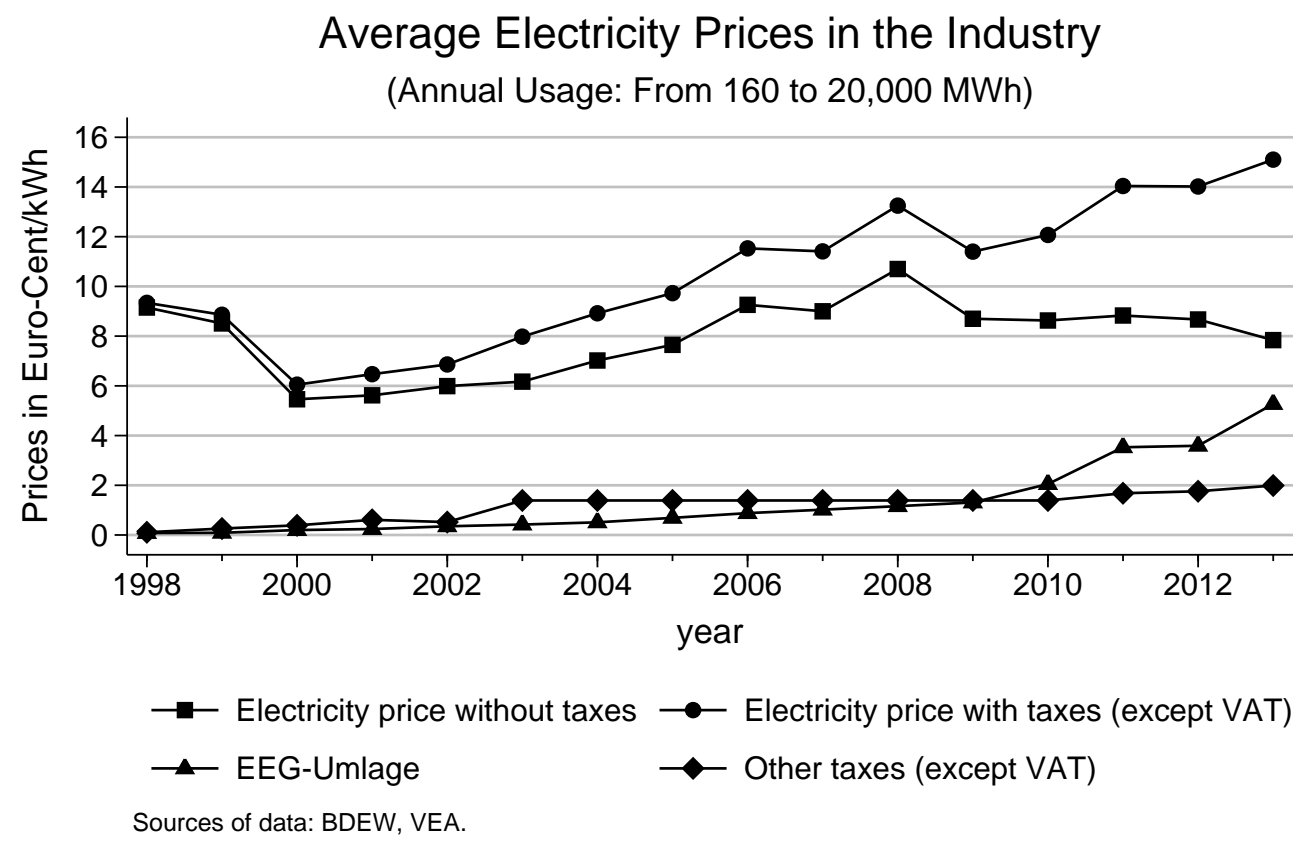

Figure 1: Electricity Prices 1998-2013

is mainly due to an increase of the Electricity Tax from 0.36 to 1.23 cent $/ \mathrm{kWh}$. The reason for the second large increase is the rise of the costs of the renewable energy surcharge since 2010. Between 2009 and 2013 the EEG surcharge quadrupled from 1.31 to 5.27 cent/kWh. Overall, the tax burden on electricity amounts to 7.26 cent/kWh in 2013 and the electricity price without taxes is 7.84 cent/kWh. Figure 2 shows the development of the consumption of electricity in Germany from 1995 to 2011. During this period the power usage in the industrial sector rose by 15 percent 


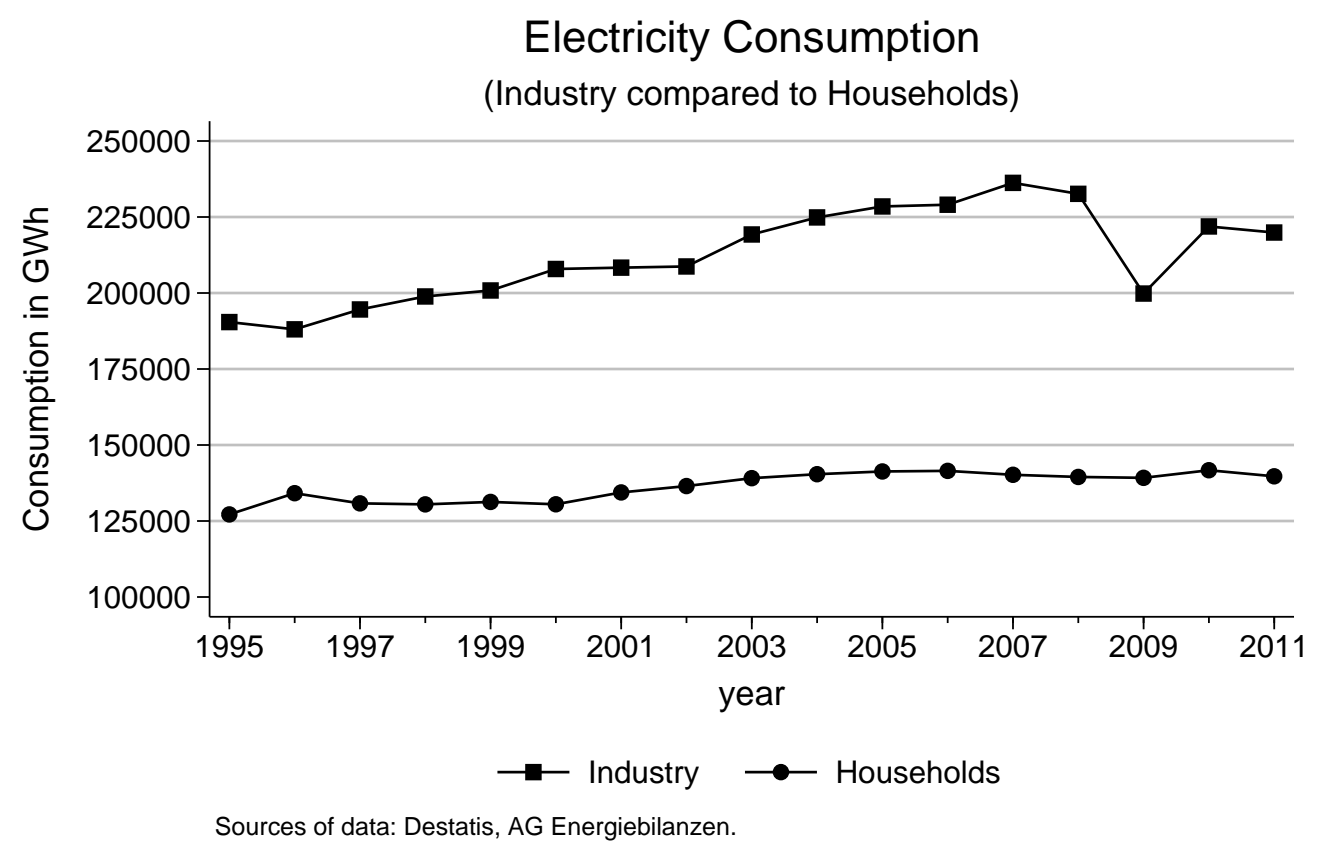

Figure 2: Electricity Consumption 1995-2011

while the consumption of private households advanced only by 10 percent. The industrial consumption increased continuously until 2008 and then tremendously declined by 14 percent in between 2008 and 2009, which is due to the recession of 2009 in Germany due to the financial crisis as the German GDP declined by approximately five percent. The GDP in the manufacturing sector (without construction) even dropped by almost 17 percent which indicates a huge decrease in industrial activity (Statistisches Bundesamt, 2010). At the same time, private consumption of electricity remained fairly stable after 2003 and was not affected by the financial crisis in 2009.

\section{Empirical Approach}

Abstracting from dynamic adjustments, we analyze the substitutability between electricity and labor using static labor demand model with multiple input factors (Hamermesh, 1993). In a first step, we use the dual approach to derive factor demand conditional on output. Hence, we focus on substitution effects only. In a second step, we account for scale effects and derive factor demand when the production 
level is adjustable (unconditional on output).

Conditional elasticities. In order to estimate the own- and cross-price elasticities of different factor inputs conditional on the level of output, we apply a translog cost function (Christensen et al., 1973). The translog cost function is superior to CobbDouglas or CES functions because it does not restrict the substitution elasticities of the input factors to be equal to one or constant. We follow the specification suggested by Diewert and Wales (1987): :

$$
\begin{aligned}
\ln C(p, Y, K) & =a_{0}+\sum_{i=1}^{n} a_{i} \ln p_{i}+b_{Y} \ln Y+c_{K} \ln K \\
& +0.5 \sum_{i=1}^{n} \sum_{j=1}^{n} a_{i j} \ln p_{i} \ln p_{j}+\sum_{i=1}^{n} b_{i Y} \ln p_{i} \ln Y+\sum_{i=1}^{n} c_{i K} \ln p_{i} \ln K \\
& +0.5 b_{Y Y} \ln Y \ln Y+c_{Y K} \ln Y \ln K+0.5 c_{K K} \ln K \ln K,
\end{aligned}
$$

where $C$ denotes the cost function given output $Y$ and input prices $p_{i}$ for $n$ input factors and $t$ stands for the time period. We also include the capital stock $K$ as a quasi-fix input factor (Hijzen and Swaim, 2010). Besides the symmetry condition $\left(a_{i j}=a_{j i}\right)$ the following restrictions must hold to ensure that the cost function is homogeneous of degree one in input prices:

$$
\sum_{i=1}^{n} a_{i}=1 \quad \sum_{j=1}^{n} a_{i j}=0 \quad \sum_{i=1}^{n} b_{i Y}=0 \quad \sum_{i=1}^{n} c_{i K}=0 .
$$

Applying Shephard's lemma $\left(\bar{X}_{i}=\frac{\partial C}{\partial p_{i}}\right)$ and making use of the generalized logfunction rule $\left(\frac{\partial \ln C}{\partial \ln p_{i}}=\frac{p_{i}}{C} \frac{\partial C}{\partial p_{i}}\right)$, we arrive at the following cost shares:

$$
S_{i}=\frac{p_{i} \overline{X_{i}}}{C}=\frac{p_{i}}{C} \frac{\partial C}{\partial p_{i}}=\frac{\partial \ln C}{\partial \ln p_{i}}=a_{i}+\sum_{j=1}^{n} a_{i j} \ln p_{j}+b_{i Y} \ln Y+c_{i K} \ln K \quad \forall i
$$

We are thus faced with a system of cost share equations, one for each input factor (electricity, high, medium and low skilled labor), which has to be estimated in order

\footnotetext{
${ }^{4}$ In order to maintain clarity, we do not include indices for sectors (unit of observation) and for time.
} 
to obtain price elasticities (Berndt and Wood, 1975). As cost shares sum up to unity, one equation has to be dropped and the system of equations has to be rewritten. Dropping equation $i=k$ and using subscripts $t$ to indicate the year and $s$ to indicate the sector, the empirical equations to be estimated read:

$$
S_{i, s t}=a_{i}+\sum_{j \neq k} a_{i j} \ln \frac{p_{j, s t}}{p_{k, s t}}+b_{i Y} \ln Y_{s t}+c_{i K} \ln K_{s t}+\tau_{i, t}+\varphi_{i, s}+\epsilon_{i, s t} \quad \forall i \neq k
$$

We estimate the coefficients of the share equation system using Zellner (1962)'s method of seemingly unrelated regressions (SUR), which turns out to be more efficient than equation-by-equation-estimation using ordinary least squares (OLS), as potential correlations of the error terms could lead to higher variances. We iterate the SUR estimation to obtain robust results with respect to the cost share to be dropped. Using the estimated coefficients and predicted costs shares, it is straightforward to calculate own-price $(i=j)$ and cross-price $(i \neq j)$ elasticities:

$$
\begin{aligned}
\bar{\mu}_{i i, s t} & =\frac{\alpha_{i i}-\hat{S}_{i, s t}+\hat{S}_{i, s t} \hat{S}_{i, s t}}{\hat{S}_{i, s t}} \\
\bar{\mu}_{i j, s t} & =\frac{\alpha_{i j}+\hat{S}_{i, s t} \hat{S}_{j, s t}}{\hat{S}_{i, s t}} .
\end{aligned}
$$

Unconditional elasticities. In order to estimate own-price and cross-price elasticities unconditional on output, we follow Hijzen and Swaim (2010) and Lichter et al. (2013) and set up the following empirical model:

$$
\ln X_{i, s t}=\sum_{j=1}^{n} \alpha_{i j} \ln p_{j, s t}+\beta_{i} \ln K_{s t}+\tau_{i, t}+\varphi_{i, s}+\epsilon_{i, s t} \quad \forall i
$$

where $X_{i, s t}$ denotes the demand for the $i^{\text {th }}$ input factor in sector $s$ in year $t$. Input prices are again given by $p_{i, s t}$, while $\epsilon_{i, s t}$ is an error term. Again, we include year $\left(\tau_{i, t}\right)$ and sector dummies $\left(\varphi_{i, s}\right)$ to control for unobserved effects as well as the log capital stock $\ln K_{s t}$ as explanatory variable. The advantage of specifying a log-linear model is obviously that we can interpret the coefficients $\alpha_{i j}$ as price elasticities. Hence, we obtain unconditional own-price elasticities $(i=j)$ and unconditional cross-price 
elasticities $(i \neq j)$ :

$$
\mu_{i j}=\frac{\partial \ln X_{i, s t}}{\partial \ln p_{j, s t}}=\alpha_{i j} \quad \forall i
$$

\section{Data}

The main database is the Linked Employer-Employee Data (LIAB) provided by the Institute of Employment Research (IAB) $5^{5}$ The LIAB data set consists of administrative social security register data on employees (a two percent random sample drawn from the administrative employment statistics from the Federal Employment Agency) as well as the IAB establishment panel which is a representative employer survey of employment parameters at individual establishments. Both micro level panels cover only employees liable to social security (which excludes self-employed and civil servants) and establishments that employ at least one of those. We use the employee data to extract information on wages and skill levels while the establishment data provides information on the firms' output and added-value product. Additionally, we use administrative data from the German Federal Employment Agency on the number of employees for several sectors on a four-digit-level.

We combine the LIAB data with information on energy usage from the Federal Statistical Office (Destatis) for numerous industrial sectors on the four-digit-level. We use information on electricity prices from Eurostat (Eurostat, 2013) including all energy-specific taxes and levies that are relevant for firms in the manufacturing sector ${ }^{6}$ We account for heterogeneous electricity prices by assigning different prices to the sectors according to their average electricity consumption.

Sample selection. We restrict our sample to the manufacturing sector due to limitations of the energy statistics which are only available in detail for this sector. The focus on manufacturing is, however, reasonable as it accounts for the the major part of the electricity consumption (44.2 percent) while the power usage in the service and public sector is rather low (24.7 percent) and therefore less relevant (International Energy Agency, 2013). Moreover, we concentrate on full-time employees

\footnotetext{
${ }^{5}$ See Alda et al. 2005$)$ for details on this data set.

6 This implies that we disregard the VAT, which is only levied on final consumption goods.
} 
who form the vast majority of manufacturing workers in our sample (94.4 percent) and distinguish between high, medium and low skilled labor. High skilled workers hold a tertiary degree from a university or college, medium skilled individuals have obtained an upper secondary school leaving certificate ("Abitur" or "Fachabitur") or finished a vocational training, or both. Low skilled workers have neither obtained an upper secondary school leaving certificate nor completed a vocational training. About three quarters of workers in our sample are assigned to the medium skilled group. In an alternative specification, we divide the labor force into blue and white collar workers. The establishment micro data is aggregated to sector levels (four digits in the industrial classification WZ2003, which is our unit of observation). Due to data availability, the sample covers the period from 2003 to 2007. For each year, our sample contains valid data for around 200 sectors which sums up to approximately 1,000 sector-year observations. All prices and wages as well as output variables are adjusted for inflation using the German consumer price index from the Federal Statistical Office.

Descriptives. Table 1 gives an overview of the descriptive statistics of the sample across sectors and years. There is a large disparity of wages across sectors, which is partly due to the fact that the skill shares vary across sectors and that there are large differences between skill levels. On average, high skilled employees earn almost twice as much as low skilled workers. The disparity between medium skilled and unskilled workers is however rather moderate. White collar workers earn on average more than blue collar workers. However, wages also vary within the skill and collar groups.7 The average electricity price is roughly 10 cents per $\mathrm{kWh}$ and varies across sectors and years in our sample. Moreover, sectors differ substantially in total employment and in the intensity of the use of electricity as an input factor. On average there are about 30,000 employees per sector and mean power usage is 1,000 MWh. Overall, the share of medium-skilled workers is about 75 percent, while high-skilled account for seven percent and unskilled workers for 20 percent of the work force. The different skill levels are distributed across white collar (28 percent)

\footnotetext{
${ }^{7}$ See Tables B.1 B.4 in the Appendix for more detailed summary statistics by two-digit sectoral levels.
} 
and blue collar workers (72 percent). Sectors also differ with respect to the number of firms. On average, a sector comprises 950 firms and produces an output of 14.5 million euros.

Table 1: Descriptive statistics on sectoral level (2003-2007)

\begin{tabular}{lcccc}
\hline Variable & Mean & Std. dev. & Min. & Max. \\
\hline Input prices & & & & \\
Overall wages (euro) & 2,598 & 690 & 729 & 5,905 \\
High skilled (euro) & 4,533 & 1,213 & 1,317 & 9,587 \\
Medium skilled (euro) & 2,629 & 645 & 746 & 6,178 \\
Low skilled (euro) & 2,319 & 554 & 761 & 6,141 \\
Blue collar (euro) & 2,440 & 568 & 760 & 5,136 \\
White collar (euro) & 3,246 & 926 & 734 & 6,163 \\
Power (cent/kWh) & 9.91 & 1.48 & 6.97 & 17.65 \\
\hline Input usage & & & & \\
Employment & 29,272 & 48,547 & 207 & 463,035 \\
Power usage (MWh) & 1,024 & 2,625 & 1 & 22,665 \\
Capital stock (million euro) & 4,410 & 5,770 & 822 & 49,100 \\
\hline Employment shares & & & & \\
High skilled & 0.07 & 0.09 & 0.00 & 0.77 \\
Medium skilled & 0.74 & 0.17 & 0.01 & 1.00 \\
Low skilled & 0.19 & 0.17 & 0.00 & 0.99 \\
White collar & 0.28 & 0.21 & 0.00 & 1.00 \\
Blue collar & 0.72 & 0.21 & 0.00 & 1.00 \\
\hline Firms & 950 & 2,228 & 5 & 17,451 \\
Number & 14.50 & 39.40 & 0.02 & 821.00 \\
Output (million euro) & & & &
\end{tabular}

Sources of data: LIAB, Destatis, Eurostat and Federal Employment Agency. Own calculations.

Combining levels of input factors and their prices gives the cost shares that we use in order to estimate conditional price elasticities. Table 2 shows the average values of the sectors' cost shares as well as their variation. It turns out that labor and electricity are on average almost equally important in the manufacturing sector. However, there is large variation across sectors. There are sectors that spend more than 89 percent of their input costs on electricity while there are others that are very labor intensive and have labor cost shares up to 86 percent. Moreover, one can 
see that labor costs for high and low skilled workers play only a minor role for the overall costs as the largest part of the labor costs can be assigned to the medium skilled employees. In addition, Table 2 illustrates the mean cost shares for blue and white collar workers. Unsurprisingly, in the manufacturing sector the cost share of blue collar workers (production labor) is on average twice as large compared to white collar workers (non-production labor). Expenses for electricity accounts for almost half of production costs, which also varies substantially across sectors ${ }^{8}$

Table 2: Cost shares of the input factors

\begin{tabular}{lccccc}
\hline Cost shares & Mean & Std. dev. & $5^{\text {th }}$ perc. & Median & $95^{\text {th }}$ perc. \\
\hline High skilled & 0.05 & 0.07 & 0.00 & 0.03 & 0.17 \\
Medium skilled & 0.40 & 0.20 & 0.07 & 0.40 & 0.72 \\
Low skilled & 0.08 & 0.08 & 0.01 & 0.05 & 0.23 \\
\hline White collar & 0.17 & 0.15 & 0.01 & 0.13 & 0.46 \\
Blue collar & 0.36 & 0.19 & 0.05 & 0.36 & 0.67 \\
\hline Labor & 0.53 & 0.23 & 0.11 & 0.56 & 0.86 \\
Electricity & 0.47 & 0.23 & 0.14 & 0.44 & 0.89 \\
\hline
\end{tabular}

Sources of data: LIAB, Destatis, Eurostat and Federal Employment Agency. Own calculations.

\section{Results}

\subsection{Conditional Elasticities}

Given that we estimate sector-year specific demand elasticities (see equation 4), we present the median values for each input in Table $\left.3\right|^{9}$ Note that we obtain similar results for the mean. Yet, using median is more robust against potential outliers. The main diagonal displays the own-price elasticities $(i=j)$ of the four input factors, which are all negative as predicted by theory. We find elasticities of -1.52 for high skilled, -0.55 for medium skilled and -1.60 for unskilled labor. Although our estimates are rather high in absolute terms, they are in line with previous findings in

8 Figure A.1 in the Appendix shows the intensity of power usage per worker for aggregated sectors on a two-digit level.

9 See Table B.5 in the Appendix for the distribution of elasticities. 
the literature and we confirm the U-shaped pattern across skill levels, which has been documented by several studies (Falk and Koebel, 1997; Fitzenberger, 1999; Peichl and Siegloch, 2012), with own-price elasticities being largest for low skilled labor. In addition, we estimate a conditional own-price elasticity of -0.2 for electricity, which indicates that the demand for electricity is rather inelastic when holding the level of output constant. This result is exactly in line with empirical findings on the industrial own price elasticities of electricity of other countries (Simmons-Süer et al., 2011).

Table 3: Medians of conditional price elasticities: Skill levels and electricity

\begin{tabular}{lcccc}
\hline \multicolumn{5}{c}{ Price } \\
\hline Demand & High skilled & Medium skilled & Unskilled & Electricity \\
\hline High skilled & $\mathbf{- 1 . 5 2}$ & 1.33 & -0.16 & $\mathbf{0 . 3 1}$ \\
Medium skilled & 0.10 & $\mathbf{- 0 . 5 5}$ & 0.26 & $\mathbf{0 . 0 9}$ \\
Unskilled & -0.11 & 1.52 & $\mathbf{- 1 . 6 0}$ & $\mathbf{0 . 1 5}$ \\
Electricity & 0.02 & 0.08 & 0.02 & $\mathbf{- 0 . 2 0}$ \\
\hline
\end{tabular}

Source: Own calculations.

The conditional cross-price elasticities are shown by the off-diagonal elements in Table 3. The last column is of particular interest for our analysis as it displays the interrelationship between heterogeneous labor and electricity. The conditional cross-price elasticity of demand for high skilled labor with respect to electricity is about 0.31 , while the cross-price elasticity of unskilled labor is 0.15 . These results indicate that there is a weak substitutability between high as well as low skilled labor and electricity. At the same time, the cross-price elasticity of medium skilled labor for electricity is about 0.09 which indicates only a very low substitutability between these two factor inputs. In another specification, we distinguish between blue and white collar workers instead of the skill level. We find conditional crossprice elasticities with respect to electricity prices of 0.18 for blue-collar workers and 0.02 for white-collar workers. See Table B.7 in the Appendix.

Our results are in line with previous findings, which usually identify a weak interrelationship between labor and electricity/energy conditional on output. However, there are mixed answers on the question, whether electricity and labor a p- 
complements or p-substitutes. Hamermesh (1993) reports that labor and energy are weak substitutes referring to a variety of studies that predominantly estimate positive but small (less than 0.2) cross-price elasticities for labor demand with respect to energy prices. Along these lines, early studies of Berndt and Wood (1975) and Pindyck and Rotemberg (1983) estimate low positive cross-price elasticities of 0.15 and 0.03 for the US indicating weak substitutability. In a more recent paper, Henriksson et al. (2012) estimate a cross-price elasticity of 0.09 in the Swedish paper industry. In contrast, Deschenes (2010) finds a negative cross-price elasticity of -0.13 for homogeneous labor with respect to electricity prices for the US.

For Germany, there are only studies that estimate price elasticities between labor and total energy consumption, and find rather mixed results. While Welsch and Ochsen (2005) estimate cross-price-elasticities of 0.19 (low-skilled labor) and 0.26 (high-skilled labor), which are very close to our results, Agnolucci (2009) finds crosselasticities to range from -0.21 to 0.04 . Falk and Koebel (2002) report elasticities of -0.285 and -0.095 for high and medium skilled workers (indicating complementarity), the value for unskilled labor is positive at 0.043 (indicating substitutability).

\subsection{Unconditional Elasticities}

So far, our results only account for the conditional factor demand, i.e., when the firms' output is held constant. We present our results for unconditional price elasticities of labor demand in Table $44^{10}$ The own-wage elasticities of high skilled, medium skilled and low skilled workers are $-0.80,-0.56$ and -2.01 . The unconditional own-wage elasticity for high-skilled labor is lower (in absolute terms) than the conditional one, which is at odds with standard theory since the scale effect is supposed to be negative. A potential reason for this inconsistency, which is, however, not uncommon in applied papers (cf. Hijzen and Swaim, 2010), could be the fact that the wage information for the high-skilled are particularly imprecisely measured because of the top-coding of wages at the social security contribution ceiling. For electricity, we find an own-price elasticity of -2.30 . Furthermore, the unconditional cross-price elasticities in terms of electricity prices are -0.69 for high skilled work-

\footnotetext{
${ }^{10}$ See Table B.6 in the Appendix for the detailed regression output.
} 
ers, -0.06 for medium skilled workers and -0.48 for workers with low skills. Again, we also estimate unconditional price-elasticities for blue and white collar labor with respect to electricity prices. We find elasticities of 0.58 for blue-collar workers and -0.82 for white-collar workers. See Table B.10 in the Appendix. Hence, for all skill groups the differences between unconditional and conditional cross-price elasticities are negative, which means that the scale effect is negative and does not reinforce the substitution effect, but even dominates the substitution effect. The interpretation of these results is that, when firms are able to adjust their production level, output is decreased due to higher input costs induced by rising electricity prices. This reduces demand for all input factors. Thus, electricity and labor seem to be moderate gross complements.

Table 4: Unconditional price elasticities: Skill levels and electricity

\begin{tabular}{lcccc}
\hline \multicolumn{5}{c}{ Price } \\
\hline Demand & High skilled & Medium skilled & Unskilled & Electricity \\
\hline High skilled & $\mathbf{- 0 . 8 0}$ & 1.56 & 0.28 & $\mathbf{- 0 . 6 9}$ \\
Medium skilled & 0.06 & $\mathbf{- 0 . 5 6}$ & 0.63 & $\mathbf{- 0 . 0 6}$ \\
Unskilled & 0.25 & 1.44 & $\mathbf{- 2 . 0 1}$ & $\mathbf{- 0 . 4 8}$ \\
Electricity & 0.05 & 0.04 & -0.01 & $\mathbf{- 2 . 3 1}$ \\
\hline
\end{tabular}

Source: Own calculations.

There is little prior evidence on unconditional cross-price elasticities between heterogeneous labor and energy for the German case. An exception is the study by Falk and Koebel (2002), which estimates scale elasticities for manufacturing sectors in Germany that are all negative ranging from -0.209 to -0.406 for high skilled labor, -0.053 to -0.082 for medium skilled workers and -0.143 to -0.087 for unskilled labor. Hence, our results are in line with these findings regarding the negative signs across all skill groups and the pattern with highest complementarity between high skilled labor and electricity, a lower complementarity for low skilled workers as well as the weakest relationship for medium skilled labor. However, our results are larger in absolute terms, especially for high and low skilled labor. This might be due to the fact that Falk and Koebel (2002) study the effect of total energy prices while we concentrate solely on electricity. Labor is more likely to 
be substitutable in production processes that include machines (electrical energy), than in production processes that are related with process heat (mainly coal and natural gas). Rising electricity prices therefore might affect employment more than other energy prices. Hence, further research should include heterogeneous energy in order to account for possible differential complementarities between various energy sources and heterogeneous labor.

\subsection{Simulation}

Our estimation results can be used to quantify by how much labor demand in the manufacturing sector would approximately change in response to a further increase in electricity prices in a back-of-the-envelope simulation (see Table 5). In 2014, the EEG surcharge will increase by 0.963 cent/kWh to 6.24 cent $/ \mathrm{kWh}$, which corresponds to an increase of the electricity price by approximately 6.7 percent. ${ }^{11}$ Based on an electricity price of 14.43 cent/kWh in 2013 for a firm with average power consumption and holding other components of the electricity price constant, our findings suggest that this increase in the electricity price would slightly decrease the demand for medium-skilled work by around 17,000 workers, which corresponds to a change of -0.4 percent, while the demand for high skilled labor would drop by 38,000 ( -4.6 percent). The demand for low skilled labor would be negatively affected by more than 30,000 workers ( -3.2 percent). Overall, employment would decrease by about 86,000 workers $(-1.4$ percent $)$.

These results suggest that, continuously rising electricity prices lower overall full-time employment in the manufacturing sector. Moreover, an increase in the price of electricity affects the composition of the demand for labor by different skill levels. While medium skilled workers are only weakly affected, there are noticeable job losses for unskilled and high skilled workers. The overall distributional incidence, however, remains unclear since both low- and high-skilled labor is affected. While rising electricity prices have a direct distributional effect on household income and it is likely that low-skilled (typically low-income) households are affected the most (in relative terms), the labor demand effects might actually counteract this effect

\footnotetext{
${ }^{11}$ See http://www.eeg-kwk.net/de/index.htm (Date: 15.11.2013).
} 
Table 5: Employment effects of an increase of the electricity price

\begin{tabular}{lcccc}
\hline Labor & Employment & Substitution Effect & Scale Effect & Overall Effect \\
\hline High skilled & 830,000 & 17,433 & $-55,488$ & $-38,055$ \\
(percent) & & $(+2.10)$ & $(-6.69)$ & $(-4.58)$ \\
Medium skilled & $4,400,000$ & 26,002 & $-43,347$ & $-17,345$ \\
(percent) & & $(+0.59)$ & $(-0.99)$ & $(-0.39)$ \\
Unskilled & 960,000 & 9,880 & $-40,404$ & $-30,524$ \\
(percent) & & $(+1.03)$ & $(-4.21)$ & $(-3.18)$ \\
\hline Total & $6,190,000$ & 53,315 & $-139,239$ & $-85,924$ \\
(percent) & & $(+0.86)$ & $(-2.25)$ & $(-1.39)$ \\
\hline
\end{tabular}

Source: Own calculations.

on inequality since the absolute income losses are higher for high-skilled (typically high-income) households. Hence, the total effect remains unclear and is left for future research with a model of the household income distribution (Bargain et al., 2012).

\section{Conclusions}

The transition from conventional and nuclear towards renewable energy sources might cause environmental improvements at the expense of negative economic effects. Therefore, from a policy perspective, it is important to pay attention to potential labor market effects of rising electricity prices. Especially for Germany, the pioneering nation in matters of renewable energies, there is little evidence on how electricity and heterogeneous labor interact.

In this paper, we estimate the cross-price elasticities between electricity and heterogeneous labor for the German manufacturing sector. We employ a static labor demand model with multiple input factors and use administrative linked employeremployee micro data combined with statistics on electricity prices and usage during the period 2003-2007. Our findings suggest that there is a weak substitutability between electricity and labor, when the production level of the firms is held constant. We find positive, but small conditional cross-price elasticities of labor demand with 
respect to electricity prices between 0.09 and 0.31 . In case of adjustable output, we find a moderate complementarity between electrical energy and labor. The scale effect dominates the substitution effect and we find negative unconditional crosselasticities ranging between -0.06 and -0.69 .

The magnitude of our estimates for cross-price elasticities varies substantially across different skill levels of labor input. While the demand for high and low skilled workers turns out to be moderately affected by electricity prices, the effect is close to zero for medium skilled workers. This is in line with previous finding on a U-shaped responsiveness of labor demand over the distribution of skills. This suggests that further increases in the price for electrical energy in Germany (e.g., due to the EEG surcharge) would result in negative employment effects in the manufacturing sector. Since we find that labor demand is affected differently across skill levels, this may result in adverse distributional impacts. A back-of-the-envelope simulation based on our estimates reveals that the announced increase of the EEG surcharge by roughly one cent per $\mathrm{kWh}$ in 2014 would decrease overall employment in the manufacturing sector by 86,000 workers, which corresponds to a decline by 1.4 percent.

However, there are several limitations to our empirical analysis. Due to data availability, we have to assume electricity prices to be homogeneous within sectors. It is however likely that larger firms pay less for each unit of electricity usage. In addition, we cannot fully capture the exemption clauses of the EEG for firms with very large electricity usage. Moreover, we cannot account for potential regional variation of electricity prices and we restrict our analysis to electricity as a the only input factor besides labor and we focus on the manufacturing sector only due to data limitations. However, electricity plays a particularly important role in this segment of the economy. Additionally, our results refer to short-term reactions to increasing electricity prices, where the capital stock is not adjustable. In future research, we plan to include further energy sources, like coal and natural gas, given that electricity can be substituted in sectors, where process heat plays an important role for the production technology (Henriksson et al., 2012). Finally, Germany's energy turnaround is an important element of the government's objective of a transition towards a "green economy". Our results only refer to employment effects in the 
manufacturing sector and we do not account for the potential creation of additional "green jobs" (Deschenes, 2013; Pestel, 2013). 


\section{References}

Agnolucci, P. (2009). The Effect of the German and British Environmental Taxation Reforms: A Simple Assessment. Energy Policy 37(8), 3043-3051.

Alda, H., S. Bender, and H. Gartner (2005). European Data Watch: The Linked Employer-Employee Dataset of the IAB (LIAB). Schmollers Jahrbuch: Journal of Applied Social Science Studies 125(2), 327-336.

Aldy, J. E. and W. A. Pizer (2011). The Competitiveness Impacts of Climate Change Mitigation Policies. NBER Working Paper No. 17705.

Bargain, O., H. Immervoll, A. Peichl, and S. Siegloch (2012). Distributional Consequences of Labor-demand Shocks: The 2008-2009 Recession in Germany. International Tax and Public Finance 19(1), 118-138.

Berndt, E. R. and D. O. Wood (1975). Technology, Prices, and the Derived Demand for Energy. Review of Economics and Statistics 57(3), 259-268.

BMU (2007). Bundesministerium für Umwelt, Naturschutz und Reaktorsicherheit - Erfahrungsbericht 2007 zum Erneuerbare-Energien-Gesetz (EEG-Erfahrungsbericht). Berlin.

Bundesverband der Energie- und Wasserwirtschaft (2013). BDEW-Strompreisanalyse Mai 2013: Haushalte und Industrie. Berlin.

Christensen, L. R., D. W. Jorgenson, and L. J. Lau (1973). Transcendental Logarithmic Production Frontiers. Review of Economics and Statistics 55(1), 28-45.

Deschenes, O. (2010). Climate Policy and Labor Markets. NBER Working Paper No. 16111.

Deschenes, O. (2013). Green Jobs. IZA Policy Paper No. 62.

Diewert, W. E. and T. J. Wales (1987). Flexible Functional Forms and Global Curvature Conditions. Econometrica 55, 43-68.

Erdmann, G. and P. Zweifel (2010). Energieökonomik. Springer, Berlin.

Eurostat (2013). Energy Statistics - Prices, Reference Metadata in Euro SDMX Metadata Structure (ESMS). Downloadable from: http://epp.eurostat.ec. europa.eu/cache/ITY_SDDS/EN/nrg_price_esms.htm (Date: 16.09.2013).

Falk, M. and Koebel (1997). The Demand of Heterogeneous Labour in Germany. ZEW Discussion Paper No. 97-28.

Falk, M. and Koebel (2002). Outsourcing, Imports and Labour Demand. Scandinavian Journal of Economics 104(4), 567-586.

Fitzenberger, B. (1999). Wages and Employment Across Skill Groups. An Analysis for West Germany. ZEW Economic Studies (6), Physica, Heidelberg. 
Frondel, M., N. Ritter, C. Schmidt, and C. Vance (2010). Economic Impacts from the Promotion of Renewable Energy Technologies: The German Experience. Energy Policy 38, 4048-4056.

Frontier Economics and EWI (2010). Energiekosten in Deutschland - Entwicklungen, Ursachen und internationaler Vergleich (Projekt 43/09), Kurzzusammenfassung des Endberichts für das Bundesministerium für Wirtschaft und Technologie. Downloadable from: http://www.ewi.uni-koeln.de/publikationen/ studien/ (Date: 03.08.2013).

Hamermesh, D. (1993). Labor Demand. Princeton University Press.

Henriksson, E., P. Söderholm, and L. Wårell (2012). Industrial Electricity Demand and Energy Efficiency Policy: The Role of Price Changes and Private R\&D in the Swedish Pulp and Paper Industry. Energy Policy 47, 437-446.

Hijzen, A. and P. Swaim (2010). Offshoring, Labour Market Institutions and the Elasticity of Labour Demand. European Economic Review 54(8), 1016-1034.

Ho, M., R. Morgenstern, and J.-S. Shih (2008). Impact of Carbon Price Policies on US Industry. RFF Discussion Paper No. 08-37.

International Energy Agency (2013). Electricity Information. Paris.

Kemfert, C. and H. Welsch (2000). Energy-Capital-Labor Substitution and the Economic Effects of CO2 Abatement: Evidence for Germany. Journal of Policy Modeling 22(6), 641-660.

Koebel, M. Falk, and F. Laisney (2003). Imposing and Testing Curvature Conditions on a Box-Cox Cost Function. Journal of Business 85 Economic Statistics 21(2), 319-335.

Küchler, S. and J. Horst (2012). Strom- und Energiekosten der Industrie: Pauschaule Vergünstigungen auf dem Prüfstand. FÖS Berlin und IZES Saarbrücken.

Lichter, A., A. Peichl, and S. Siegloch (2013). Exporting and Labor Demand: MicroLevel Evidence from Germany. IZA Discussion Paper No. 7494.

Peichl, A. and S. Siegloch (2012). Accounting for Labor Demand Effects in Structural Labor Supply Models. Labour Economics 19(1), 129-138.

Pestel, N. (2013). Green Jobs: Erlebt Deutschland sein grünes Beschäftigungswunder? IZA Standpunkte Nr. 58, Bonn.

Pindyck, R. S. and J. J. Rotemberg (1983). Dynamic Factor Demands and the Effects of Energy Price Shocks. American Economic Review 73(5), 1066-1079.

Sensfuß, F. (2011). Analysen zum Merit-Order Effekt erneuerbarer Energien: Update für das Jahr 2010. Fraunhofer Institut, Karlsruhe.

Simmons-Süer, B., E. Atukeren, and C. Busch (2011). Elastizitäten und Substitutionsmöglichkeiten der Elektrizitätsnachfrage: Literaturübersicht mit besonderem Fokus auf den Schweizer Strommarkt. KOF Studien, No. 26. 
Statistisches Bundesamt (2010). Bruttoinlandsprodukt 2009 für Deutschland. Wiesbaden.

Statistisches Bundesamt (2013). Online-Datenbank Genesis. Unternehmen (Unternehmensregister-System 95): Deutschland, Jahre, Wirtschaftszweige (Abschnitte), Beschäftigtengrößenklassen, Code: 52111-0001. Downloadable from: WwW.genesis.destatis.de/genesis/online (Date: 29.08.2013).

Umweltbundesamt (2013). Treibhausgasausstoß in Deutschland 2012 - vorläufige Zahlen aufgrund erster Berechnungen und Schätzungen des Umweltbundesamtes. Dessau-Roßlau.

Welsch, H. and C. Ochsen (2005). The Determinants of Aggregate Energy Use in West Germany: Factor Substitution, Technological Change, and Trade. Energy Economics 27(1), 93-111.

Zellner, A. (1962). An Efficient Method of Estimating Seemingly Unrelated Regressions and Tests for Aggregation Bias. Journal of the American Statistical Association 57(298), 348-368. 


\section{Appendix}

\section{A Graphs}

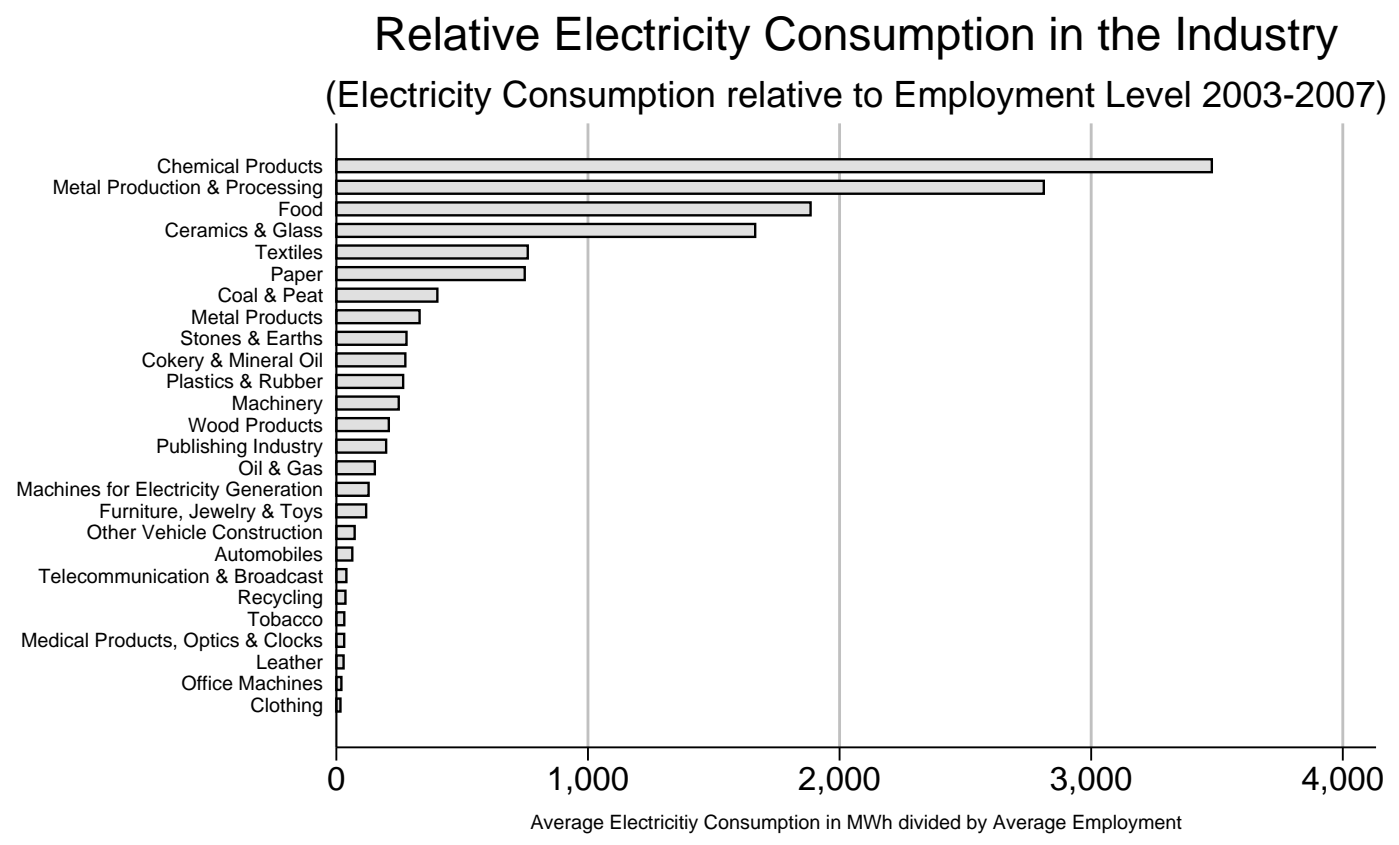

Sources of data: Destatis, Federal Employment Agency. Calculations: own.

Figure A.1: Intensity of Electricity Consumption

\section{B Tables}


Table B.1: Cross-tabulation of skill levels and collar types (2003-2007)

\begin{tabular}{lcccc}
\hline \multicolumn{4}{c}{ Qualification } \\
\hline Collar type & High skilled & Medium skilled & Unskilled & Total \\
\hline Blue collar & 67,491 & $2,197,379$ & 580,117 & $2,844,987$ \\
(row percentages) & $(2.37)$ & $(77.24)$ & $(20.39)$ & $(100)$ \\
[column percentages] & {$[12.47]$} & {$[76.62]$} & {$[92.69]$} & {$[70.51]$} \\
White collar & 473,665 & 670,351 & 45,775 & $1,189,791$ \\
(row percentages) & $(39.81)$ & $(56.34)$ & $(3.85)$ & $(100)$ \\
[column percentages] & {$[87.53]$} & {$[23.38]$} & {$[7.31]$} & {$[29.49]$} \\
Total & 541,156 & $2,867,730$ & 625,892 & $4,034,778$ \\
(row percentages) & $(13.41)$ & $(71.08)$ & $(15.51)$ & $(100)$ \\
[column percentages] & {$[100]$} & {$[100]$} & {$[100]$} & {$[100]$} \\
\hline
\end{tabular}

Source of data: LIAB. 


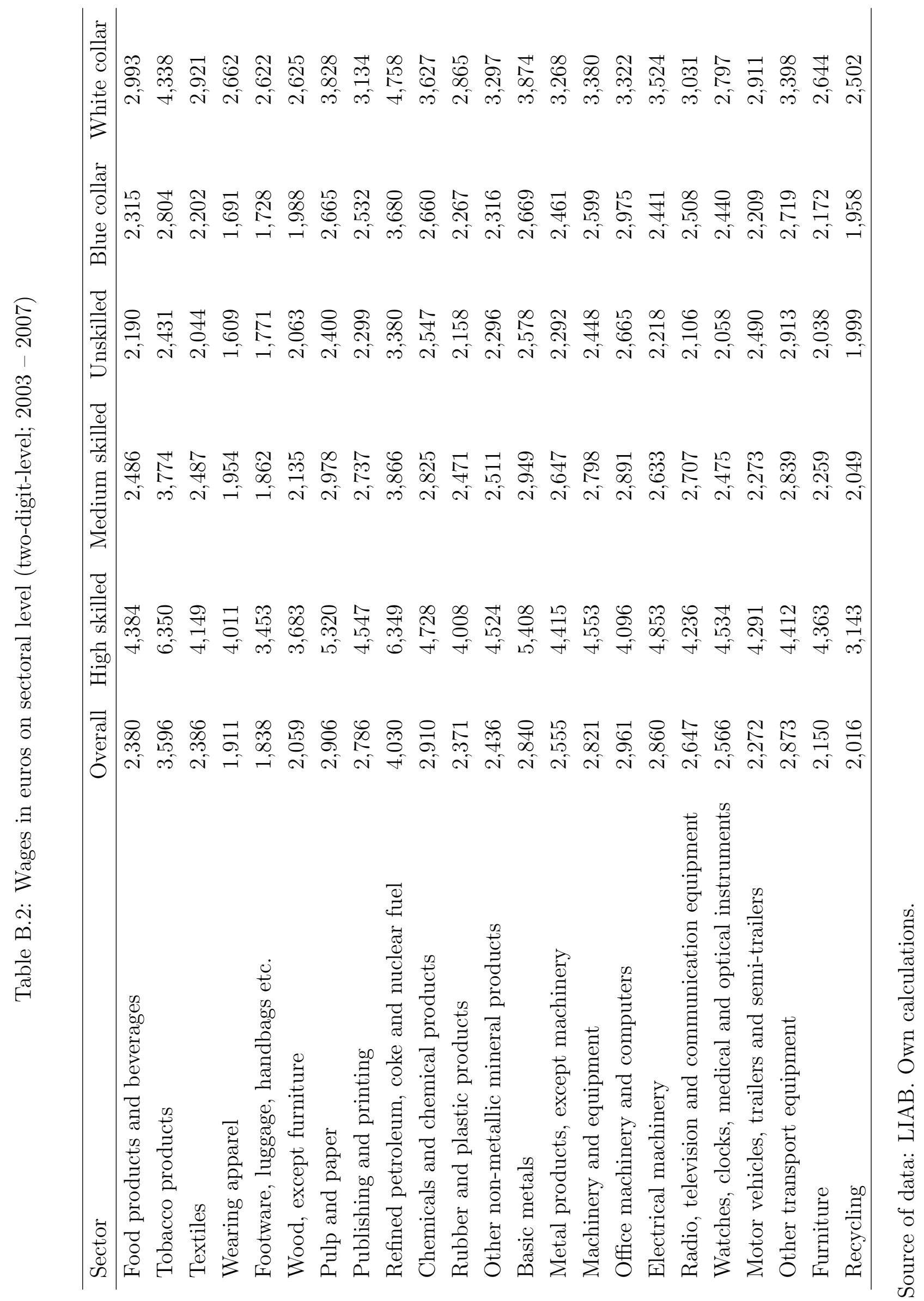




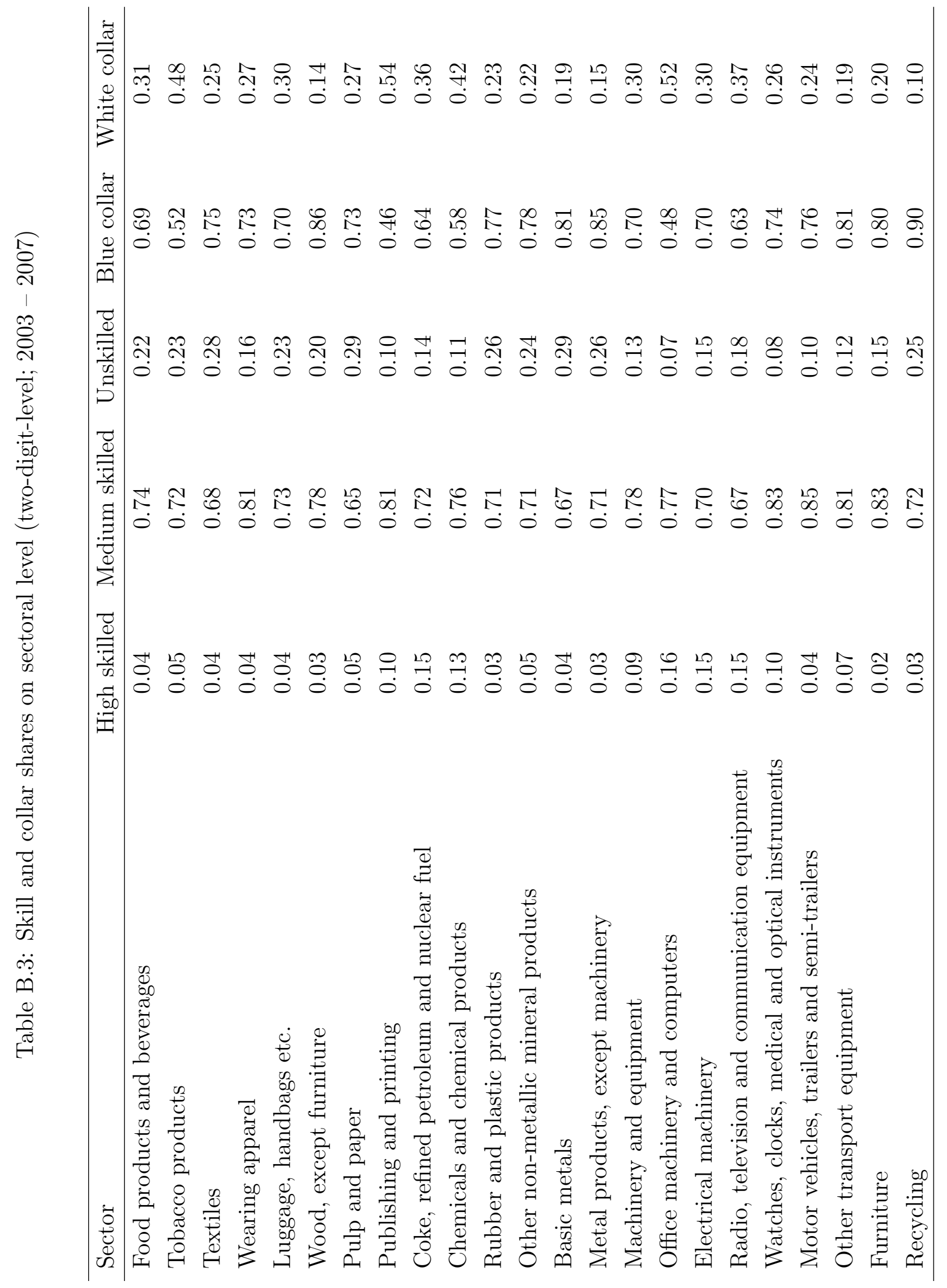






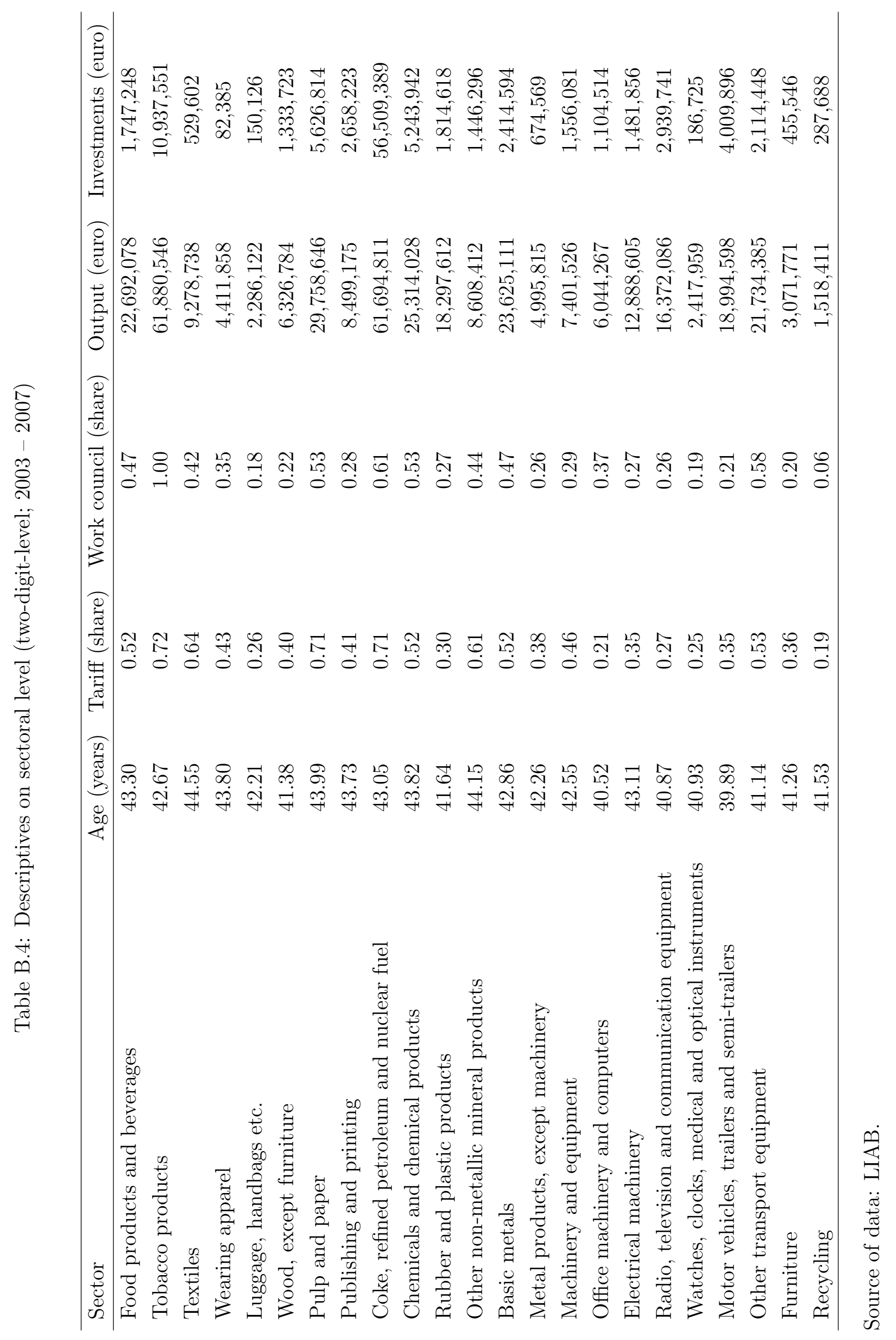




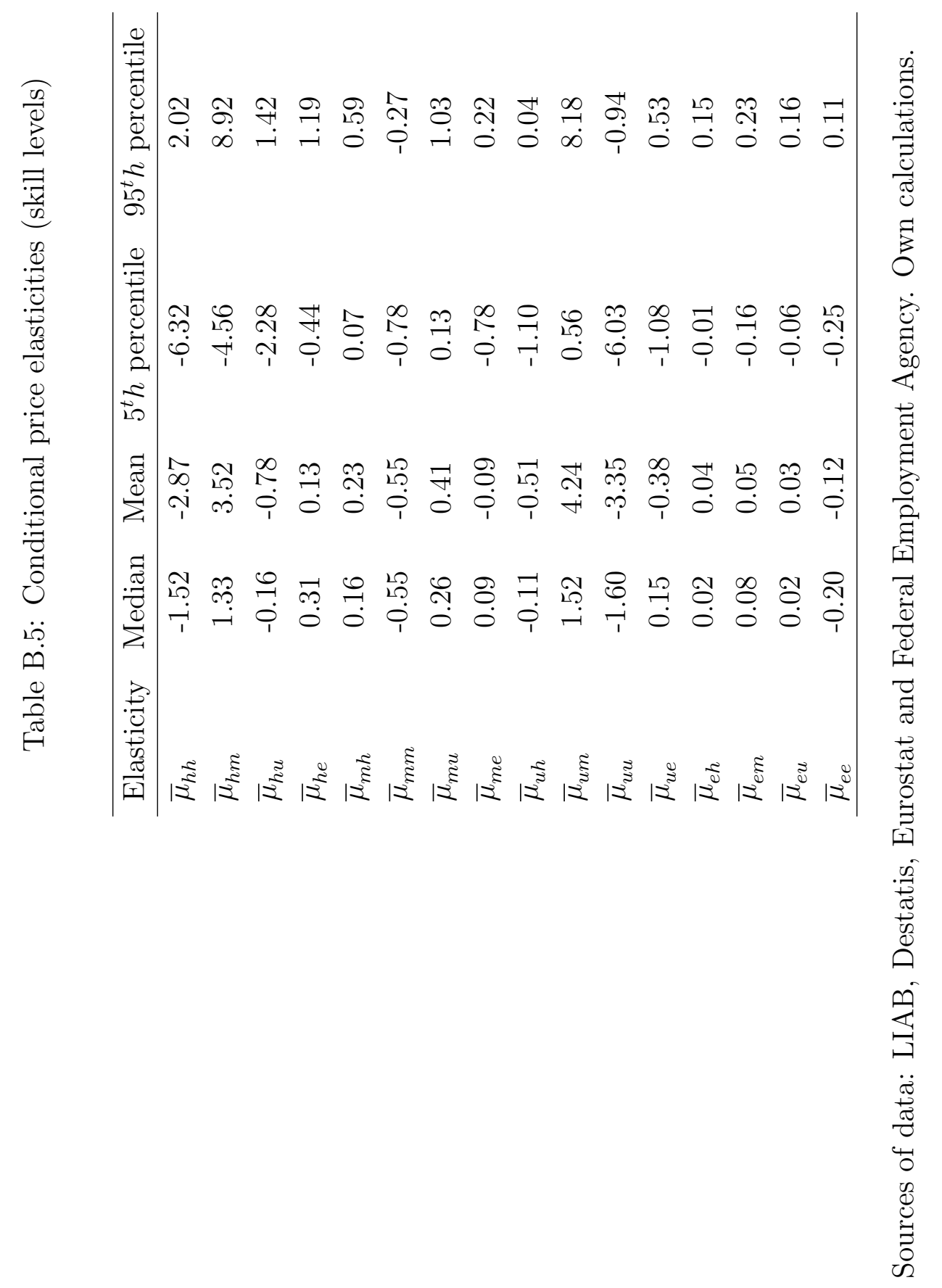




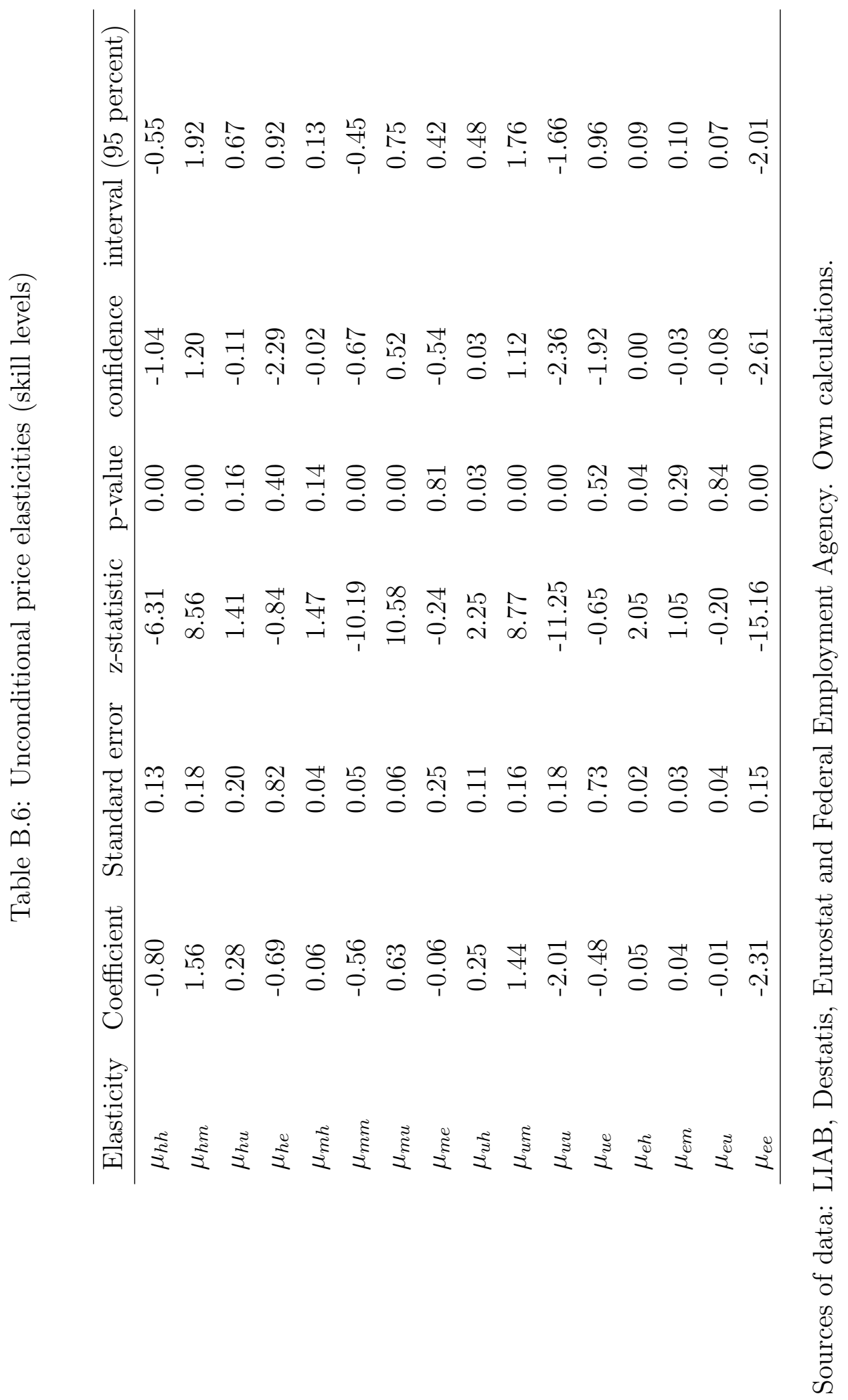


Table B.7: Medians of conditional price elasticities: Collar groups

\begin{tabular}{lccc}
\hline & \multicolumn{3}{c}{ Price } \\
\hline Demand & Blue collar & White collar & Electricity \\
\hline Blue collar & $\mathbf{- 0 . 5 9 7 3}$ & 0.3763 & $\mathbf{0 . 1 7 7 8}$ \\
White collar & 0.8599 & $\mathbf{- 0 . 9 3 4 5}$ & $\mathbf{0 . 0 1 9 8}$ \\
Electricity & 0.1557 & 0.0045 & $\mathbf{- 0 . 2 0 8 7}$ \\
\hline
\end{tabular}




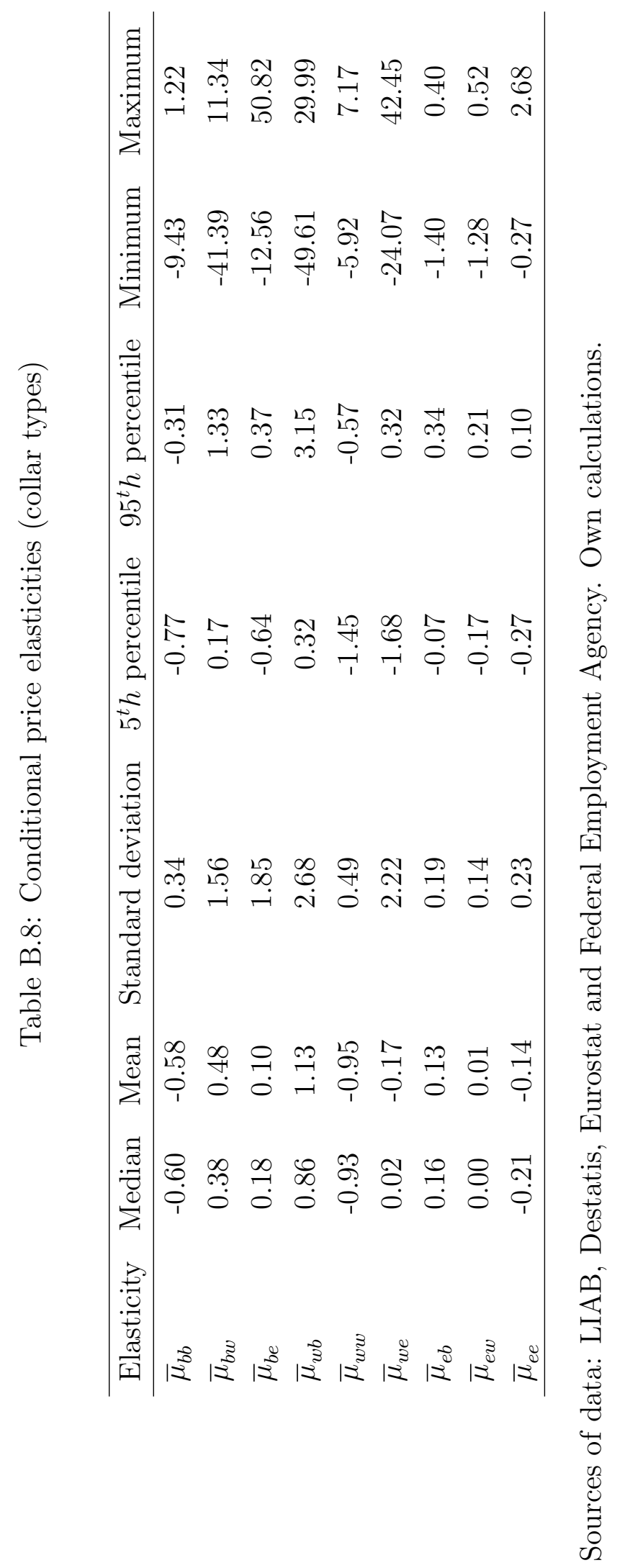


Table B.9: Unconditional price elasticities: Collar groups

\begin{tabular}{lccc}
\hline & \multicolumn{3}{c}{ Price } \\
\hline Demand & Blue collar & White collar & Electricity \\
\hline Blue collar & $\mathbf{- 0 . 6 0 7 9}$ & 0.5234 & $\mathbf{0 . 5 7 7 8}$ \\
White collar & 1.7686 & $\mathbf{- 1 . 0 8 0 9}$ & $\mathbf{- 0 . 8 1 6 7}$ \\
Electricity & 0.1105 & -0.0290 & $\mathbf{- 2 . 3 1 9 0}$ \\
\hline
\end{tabular}




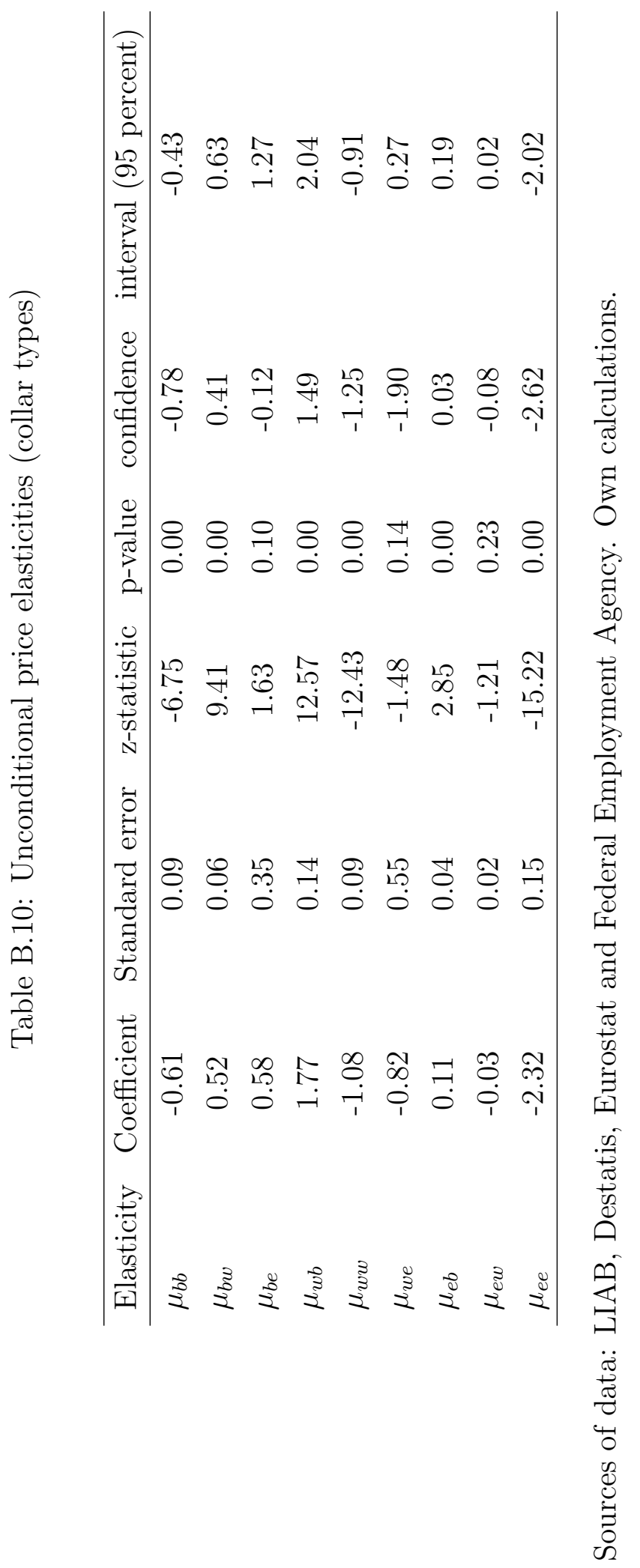

